\title{
Effect of sub-acute and sub-chronic administration of Vicia faba's cooking medium containing EDTA on hepato-renal functions in albino mice
}

\author{
Sabry Ali El-Naggar \\ Tanta University \\ Mona Elwan \\ Tanta University \\ Doaa Ibrahim Kabil \\ Tanta University \\ Abdelaziz Zidan \\ Damanhour University \\ Karim El-Said ( $\nabla$ kareem.ali@science.tanta.edu.eg ) \\ Tanta University Faculty of Science
}

\section{Research Article}

Keywords: Vicia faba, EDTA, Sub-acute, Sub-chronic, Toxicity, Antioxidants

Posted Date: November 9th, 2021

DOI: https://doi.org/10.21203/rs.3.rs-918122/v1

License: (9) This work is licensed under a Creative Commons Attribution 4.0 International License. Read Full License 


\section{Abstract}

To decrease the Vicia faba beans cooking time, some chefs added ethylene diamine tetra-acetic acid (EDTA) during the cooking process. This study addressed the effect of sub-acute and chronic administrations of faba bean's cooking media containing EDTA (C.M./EDTA) on hepato-renal functions in mice. Ninety male mice were divided into three groups $(n=30)$. The group 1 (Gp1) divided into Gp1a and $\mathrm{Gp} 1 \mathrm{~b}$, both were served as control for sub-acute and sub-chronic treatments. Gp2 divided into Gp2a and Gp2b then administered with $200 \mu$ l of C.M. for 15 and 90 days, respectively. Gp3 divided into Gp3a and Gp3b then administered $200 \mu \mathrm{l}$ of C.M./EDTA $(10 \mathrm{mg} / \mathrm{kg}$ ) for 15 and 90 days, respectively. Hematological, biochemical, and histopathological alterations were investigated. The results showed that sub-acute administration of C.M./EDTA did not show any signs of toxicity, however, sub-chronic administration showed substantial toxicity evidenced by alterations in some biochemical and histological investigations.

\section{Introduction}

Faba bean (Vicia faba, L.) is an important legume crop used for human and animal nutrition (Hefni and Witthoft 2014). It belongs to family Fabaceae (Leguminosae). $V$. faba beans are rich with macro-nutrients such as carbohydrates (58\%), lipids (2\%), proteins (26\%) and micronutrients such as vitamins, minerals. Secondary metabolites including phenolics, flavonoid and other constitutes were reported (Baginsky et al. 2013). Due to their nutritional importance, people have shifted their consumption to $V$. faba as a protein source instead of animal proteins. The seed of $V$. faba beans is very hard, therefore, the time of cooking process of these beans are relatively long (Farajvand et al. 2017; El-Naggar et al. 2020). For this reason, different additives were used to decrease the time of cooking process. Among of them, some chemicals were routinely added to increase the cooking process such as sodium bicarbonate, citric acid (Laniga et al. 2002; Lamas et al. 2014).

Ethylene diamine tetra-acetic acid (EDTA) is a chelator agent, potentially used for vascular disease treatment, keratopathy and increased the efficacy of chemotherapy (Kobayashi et al. 2015; Ferrero 2016; El-Naggar et al. 2019a; El-Naggar et al. 2019b). EDTA may inhibit bleomycin nuclease activity, which in turn induces cancer cell apoptosis (Feril et al. 2017). Recently, unfortunately some chefs added EDTA to decrease faba beans cooking time from 9 hours to only 90 minutes (El-Naggar et al. 2019c). Previous study showed that EDTA addition to black beans (P. vulgaris $L$.) decreased starch gelatinization degree (Mubaiwa et al. 2017). Very few reports demonstrated the effect of EDTA addition during the cooking process on the nutritional and toxicological levels. In our previous study, we have reported that EDTA addition to faba beans during the cooking process decreased the nutritional values of macronutrient (ElNaggar et al. 2019c). In addition, it has been reported that cooking of faba beans in presence of EDTA decreased the levels of minerals, but not affect the levels of vitamins. Furthermore, it was reported that addition of EDTA during the cooking process of faba beans deceased their phytochemical contents of phenolic, flavonoid, anthocyanin and saponin contents. EDTA addition to faba beans during cooking process also decreased, increased, and diminished some phytochemicals constitute (El-Nashrty 2021). 
Acute administration of EDTA may cause gastrointestinal upset, kidney injury, transient bone marrow depression and muscle cramps (Bingham et al. 2001). EDTA administration also decreased coagulation factor activity and some biochemical parameters in the serum (Khalil et al. 2008). Administration of 750 $\mathrm{mg} / \mathrm{kg} /$ day of EDTA was reported as the lowest dose that caused a toxic effect and induce DNA damage or chromosomal breaking in human and mice with no carcinogenic effects (Lanigan and Yamarik 2002). Recently, in vivo study showed that the administration of C.M./EDTA (20 or $40 \mathrm{mg} / \mathrm{Kg}$ ) for 90 days caused pathophysiological alterations evidenced by increase the adverse of liver and kidney function biomarkers in mice (El-Naggar et al. 2019a). Therefore, this study was extended to address the adverse effect of sub-acute and chronic administrations of C.M./EDTA $(10 \mathrm{mg} / \mathrm{Kg})$ on hepato-renal functions in experimental mice.

\section{Materials And Methods}

\section{Chemicals}

EDTA was purchased from Sigma-Aldrich. Biochemical kits for alanine aminotransferase (ALT), aspartate aminotransferase (AST), urea, creatinine, cholesterol, triglycerides, HDL, LDLcholesterol, malondialdehyde (MDA), reduced glutathione (GSH), catalase (CAT), and superoxide dismutase (SOD) kits were purchased from Biodiagnostic (El-Dokky, Egypt).

\section{Preparation of cooking media containing EDTA}

Fifty grams of Vica faba beans (faba seeds) was completed to $500 \mathrm{ml}$ distilled water in presence of $1 \mathrm{~g}$ of EDTA/L. Faba seeds were cooked for 90 minutes and then the C.M. was filtered and stored at $-20{ }^{\circ} \mathrm{C}$ until use. $50 \mathrm{~g}$ of faba seeds were completed to $500 \mathrm{ml}$ of distilled water and boiled under the same condition and the C.M. was used as a negative control.

\section{Mice and experimental design}

Male albino mice with average weights $20 \pm 2 \mathrm{~g}$ were obtained from National Research Center (NRC, Cairo, Egypt). Mice were kept at the Animal Facility, Zoology Department, Faculty of Science, Tanta University. Mice were housed under standard laboratory condition of temperature and humidity according to the suggested National ethical guidelines for the care of laboratory animals as the Animal Ethics Committee, Faculty of Science, Tanta University, Egypt. The institutional animal care committee at the Zoology Department, Faculty of Science, Tanta University-Egypt, approved the experimental design (IACUC-SCI-TU-0098).

Post a week of adaptation, mice were divided into three groups ( $n=30)$. The group 1 (Gp1) further divided into two subgroups (Gp1a and Gp1b), both of them were served as control for 15 days (subacute) and 90 days (chronic) of administrations. Gp2 was divided into two subgroups (Gp2a and Gp2b) that administered orally with $200 \mu \mathrm{l}$ of C.M. for 15 and 90 days, respectively. Gp3 was divided into two subgroups (Gp3a and Gp3b) that administered orally with $200 \mu \mathrm{l}$ of C.M./EDTA (10 mg/kg) for 15 and 90 
days, respectively. Blood samples were collected via orbital plexus bleeding for hematological and biochemical analysis and then mice were sacrificed to harvest liver and kidney tissues for histopathological examinations.

\section{Determination of hematological and biochemical parameters}

The blood was withdrawn from retro-orbital plexus to estimate the total red blood cells (R.B.Cs), hemoglobin content $(\mathrm{Hb})$, hematocrit (Hct\%), the total white blood cells (W.B.Cs) and differential count using auto hematology analyzer (BC-3200, Mindray, China). Biochemically, serum ALT, AST, urea, and creatinine were assayed by the colorimetric method using kit (Diamond-Diagnostics, Egypt). Furthermore, serum cholesterol, triglycerides, and HDL-cholesterol were determined using quantitative kit based on the previously described methods (Burstein et al. 1970; Allain et al. 1974; Fossati and Prencipe, 1982). LDL was calculated according to Friedewald et al. (1972) as follows: LDL = total cholesterol- HDLVLDL. MDA was assessed based on the method that have been previously described by Li and Chow, 1994. According to Paglia and Valentine, (1967), the levels of GSH was determined. Catalase activities were measured following the methodology of Aebi, (1984). SOD activity was determined as described by Paoletti and Mocali, (1990).

\section{Histopathology investigations}

Liver and kidney tissues of the experimental groups under the study were collected. Small pieces were immediately fixed in $10 \%$ neutral buffered formalin for 24 hours. The tissue samples were dehydrated in ascending grades of ethyl alcohol, cleared by xylene, and embedded in paraffin. Sections of $5 \mu$ thickness were mounted and stained with haematoxylin and eosin (HandE) (Bancroft and Gamble, 2002). All slide preparations were microscopically examined for the histopathological investigation.

\section{Statistical analysis}

Dunnet test was used to compare all groups against the control group to show the significant effect of treatment. The criterion for statistical significance was set at $p<0.05$. All data are presented as mean \pm SD.

\section{Results}

\section{Subacute and sub-chronic administrations of C.M./EDTA did not influence body weight changes}

Administration of C.M. alone for 15 days (Gp2a) or 90 days (Gp2b) orally did not induce changes in body weight when compared to their control group. Also, administration of C.M./EDTA for 15 days (Gp3a) or 90 days (Gp3b) did not decrease the body weight of mice post 15 and 90 days of the administrations (Fig. 1A). The percentages of body weight changes (\% b.wt) in Gp1a, Gp2a, and Gp3a post 15-days of 
administration were $28.1,30.3$, and $28.2 \%$, respectively. While the \% b.wt in Gp1b, Gp2b, and Gp3b post 90-days of administration were $43.6,41.1$, and $40.2 \%$, respectively (Fig. 1B).

\section{Sub-chronic but not sub-acute administration did alter some hematological parameters}

The results showed that there were no significant changes in the hematological parameters post 15 days of administration (subacute) either with C.M. alone (Gp2a) or with C.M./EDTA (10 mg/kg) (Gp3a) when compared to their control group. Post 90 days of administration (sub-chronic) with C.M. alone, the differential leucocytes count did not alter when compared to control group. Administration with C.M./EDTA for the same time did change these percentages when compared to Gp1b and Gp2b (Table 1).

Table 1

Total leucocyte counts and their differential percentages post 90 days of administration.

\begin{tabular}{|c|c|c|c|c|}
\hline \multirow[t]{2}{*}{ Groups } & \multirow{2}{*}{$\begin{array}{l}\text { W.B.Cs } \\
\left(\times 10^{3} / \mathrm{ul}\right)\end{array}$} & \multicolumn{3}{|c|}{ Differential leucocyte count } \\
\hline & & Lymph. (\%) & Neut. (\%) & Mono. (\%) \\
\hline Gp1b & $9.2 \pm 1.7$ & $81.7 \pm 2.5$ & $14.5 \pm 2.0$ & $4.7 \pm 2.0$ \\
\hline Gp2b & $9.5 \pm 2.8$ & $79.5 \pm 4.5$ & $11.5 \pm 1.5$ & $6.7 \pm 2.2$ \\
\hline Gp3b & $8.5 \pm 1.9$ & $55.4 \pm 5.5^{\star}$ & $28.7 \pm 2.9 *$ & $8.5 \pm 1.9 *$ \\
\hline \multicolumn{5}{|c|}{$\begin{array}{l}\text { Gp1b: control administered with } \mathrm{H}_{2} \mathrm{O}, \mathrm{Gp} 2 \mathrm{~b} \text { : mice administered with cooking media (C.M.) alone for } \\
90 \text { days, Gp3b: mice administered with C.M./EDTA }(10 \mathrm{mg} / \mathrm{Kg}) \text { for } 90 \text { days. * Means significant } \\
\text { change }(\mathrm{p} \geq 0.05) \text {. }\end{array}$} \\
\hline
\end{tabular}

Sub-chronic administration of C.M./EDTA altered liver transaminases, urea, and creatinine levels

Administration of C.M. alone (Gp2a) or C.M./EDTA (10 mg/kg) (Gp3a) for 15 days (subacute) led to no significant changes in the ALT, AST, urea, and creatinine levels when compared to their control group (Gp1a). Post 90 days of administration with C.M. alone (Gp2b), this parameter did not alter when compared to control group (Gp1b). Sub-chronic administration of C.M./EDTA (10 mg/kg) (Gp3b) increased these parameters in sera when compared to control group (Gp1b) (Table 2). 
Table 2

ALT, AST activities, urea, and creatinine levels post 15 and 90 days of administration.

\begin{tabular}{|c|c|c|c|c|}
\hline Groups & $\begin{array}{l}\text { ALT } \\
(U / L)\end{array}$ & $\begin{array}{l}\text { AST } \\
(U / L)\end{array}$ & Urea (mg/dl) & $\begin{array}{l}\text { Creatinine } \\
(\mathrm{mg} / \mathrm{dl})\end{array}$ \\
\hline \multicolumn{5}{|c|}{ Post 15-days (Sub-acute) } \\
\hline Gp1a & $52.3 \pm 1.7$ & $210.8 \pm 6.5$ & $42.5 \pm 0.6$ & $0.42 \pm 0.06$ \\
\hline Gp2a & $52.3 \pm 1.0$ & $233.5 \pm 5.3$ & $46.3 \pm 0.9$ & $0.45 \pm 0.08$ \\
\hline Gp3a & $42.3 \pm 1.3$ & $242.5 \pm 6.3$ & $48.7 \pm 0.7$ & $0.41 \pm 0.05$ \\
\hline \multicolumn{5}{|c|}{ Post 90-days (Sub-chronic) } \\
\hline Gp1b & $49 \pm 0.9$ & $179.6 \pm 2.1$ & $38.89 \pm 0.9$ & $0.35 \pm 0.06$ \\
\hline Gp2b & $62 \pm 1.1$ & $185.5 \pm 3.2$ & $41.24 \pm 0.8$ & $0.49 \pm 0.02$ \\
\hline Gp3b & $88 \pm 0.5^{\star}$ & $197.5 \pm 2.8$ & $48.35 \pm 1^{*}$ & $0.87 \pm 0.03^{\star}$ \\
\hline \multicolumn{5}{|c|}{$\begin{array}{l}\text { Gp1a and Gp1b: control administered with } \mathrm{H}_{2} \mathrm{O}, \mathrm{Gp} 2 \mathrm{a} \text { and } \mathrm{Gp} 2 \mathrm{~b} \text { : mice administered with cooking } \\
\text { media (C.M.) alone, Gp3a and Gp3b: mice administered with C.M./EDTA ( } 10 \mathrm{mg} / \mathrm{Kg} \text { ) Gp1a, Gp2a, an } \\
\text { Gp3a were administrated for } 15 \text { days, Gp1b, Gp2b, and Gp3b were administrated for } 90 \text { days. ALT: } \\
\text { Alanine transaminase, AST: Aspartate transaminase. * Means significant change ( } \geq 0.05) \text {. }\end{array}$} \\
\hline
\end{tabular}

\section{Cooking media/EDTA did not affect the lipids profile post 90 days of administration}

Administration with C.M. alone (Gp2a) or with C.M./EDTA (Gp3a) for 15 days did not change the levels of cholesterol, triglycerides, HDL-C, and LDL-C in sera when compared to control (Gp1a). Similarly, lipids profile was detected when mice were administered for 90 days either with C.M. alone (Gp2b) or with C.M./EDTA (Gp3b) when compared to their levels in control (Gp1b) (Table 3). 
Table 3

Lipids profile post 15 and 90 days of administration.

\begin{tabular}{|c|c|c|c|c|}
\hline Groups & Cholesterol (mg/L) & Triglycerides $(\mathrm{mg} / \mathrm{dL})$ & $\begin{array}{l}\text { HDL-C } \\
(\mathrm{mg} / \mathrm{dL})\end{array}$ & $\begin{array}{l}\text { LDL-C } \\
(\mathrm{mg} / \mathrm{dL})\end{array}$ \\
\hline \multicolumn{5}{|c|}{ Post 15-days (Sub-acute) } \\
\hline Gp1a & $113.5 \pm 1.4$ & $115.5 \pm 11.6$ & $78.5 \pm 1.5$ & $13.5 \pm 1.7$ \\
\hline Gp2a & $115.8 \pm 1.4$ & $120.5 \pm 11.7$ & $70.3 \pm 1.5$ & $12.5 \pm 1.3$ \\
\hline Gp3a & $110.2 \pm 1.2$ & $103.7 \pm 11.5$ & $82.5 \pm 2.16$ & $14.2 \pm 1.4$ \\
\hline \multicolumn{5}{|c|}{ Post 90-days (Sub-chronic) } \\
\hline Gp1a & $116 \pm 1.8$ & $119.5 \pm 13.7$ & $83.7 \pm 1.5$ & $15.5 \pm 1.2$ \\
\hline Gp2a & $125 \pm 1.9$ & $135.5 \pm 12.6$ & $76.3 \pm 1.5$ & $14.5 \pm 1.8$ \\
\hline Gp3a & $130.25 \pm 1.5$ & $101.5 \pm 12.8$ & $72 \pm 2.6$ & $19.25 \pm 1.9$ \\
\hline \multicolumn{5}{|c|}{$\begin{array}{l}\text { Gp1a and Gp1b: control administered with } \mathrm{H}_{2} \mathrm{O}, \mathrm{Gp} 2 \mathrm{a} \text { and } \mathrm{Gp} 2 \mathrm{~b} \text { : mice administered with cooking } \\
\text { media (C.M.) alone, Gp3a and Gp3b: mice administered with C.M./EDTA ( } 10 \mathrm{mg} / \mathrm{Kg}) \mathrm{Gp} 1 \mathrm{a}, \mathrm{Gp} 2 \mathrm{a} \text {, an } \\
\text { Gp3a were administrated for } 15 \text { days, Gp1b, Gp2b, and Gp3b were administrated for } 90 \text { days. HDL-C: } \\
\text { High density lipoprotein-Cholesterol, LDL-C: Low density lipoprotein-Cholesterol. * Means significant } \\
\text { change ( } \geq \geq 0.05) \text {. }\end{array}$} \\
\hline
\end{tabular}

Sub-acute administration did not oxidants/antioxidants biomarkers however, sub-chronic administration did

Oxidant/antioxidant biomarkers (MDA, GSH, CAT, and SOD) were measured 15- and 90-days post administration of different groups. The results showed that sub-acute and sub-chronic administrations of C.M. alone did not alter these biomarkers. Sub-acute administration of C.M./EDTA (Gp3a) did not alter these biomarkers (Fig. 2), however, chronic administration of C.M./EDTA (10 mg/kg) (Gp3b) did increase MDA, and decrease GSH levels, SOD, and CAT activities when compared to control group (Gp1b) (Fig. 3).

\section{Administration of C.M./EDTA for 90 days altered the architectures of liver and kidney tissues}

Liver section of mice administered with C.M alone for 15 days (Gp2a) showed normal central veins (Cv), normal hepatic strands $(H)$, some hepatocytes are degenerated and vacuolated $(V)$, others are binucleated (arrows), regular blood sinusoids with distinct phagocytic Kupffer cells (double arrows). Liver section of mice administered with C.M./ EDTA (10 mg/Kg) for 15 days (Gp3a) displaying organized hepatic architecture and central vein (Cv), few cellular infiltrations (arrow) and Kupffer cells (K) were noticed. Some histopathological alterations were seen in liver sections obtained from mice administered for 90 days with C.M./EDTA (Gp3b), including cellular disorganization, degeneration, necrosis of many hepatocytes especially in the centrilobular zone and cytoplasmic vacuolation, pronounced nuclear 
changes, karyolitic nuclei and pleomorphic ones as well as dilated and congested central vein with cellular infiltration and accumulation of large dark brown pigments in its lumen (Fig. 2C).

Kidney sections of mice administered either with C.M. alone (Gp1a) or with C.M./EDTA (Gp3a) for 15 days exhibiting normal like structure of the renal tissue, normal glomeruli with regular Bowman's space $(*)$, mostly renal tubules are normal (R), few numbers are dilated and damaged (arrows). However, kidney sections of mice administered with C.M./EDTA $(10 \mathrm{mg} / \mathrm{Kg}$ ) for 90 days (chronic) displaying disorganized glomeruli $(\mathrm{G})$ with narrow Bowman's space $\left({ }^{\star}\right)$, mostly renal tubules are damaged, destructed and atrophy of its lining epithelia $(R)$, others are intermixed with each other (thin arrow) and intratubular hemorrhage was damaged (thick arrow) (Fig. 2C).

\section{Discussion}

Faba bean ( $V$. faba, L.) is a popular nutritional legume crop in most countries around the world (Hefni and Witthoft 2014). EDTA and its salt derivatives have been widely used in the field of food industry. Prolonged oral administration of EDTA could be toxic depending on the administration route and the doses (Ramadan et al. 2016). Previous studies reported that cooking could alter phytochemicals constitute and hence influence the bioactive compounds and antioxidant capacity in food (Podsedek et al. 2008; Chan et al. 2009; Rawson et al. 2013; Gunathilake et al. 2018). Using of chemicals in cooking negatively affect the nutritional value of faba seeds and could be harmful upon eating on human health (El-Naggar et al. 2019a; El-Naggar et al. 2019b).

This study was conducted to evaluate the effect of subacute and chronic administration of C.M./EDTA $(10 \mathrm{mg} / \mathrm{Kg}$ ) on the hepatorenal functions in the experimental mice. Previous study showed that administration of $20 \mathrm{mg} / \mathrm{Kg}$ or $200 \mathrm{mg} / \mathrm{Kg}$ led to toxic effects on the liver and kidney tissues in experimental animals that evidenced by the increase in ALT, AST, urea, and creatinine biomarkers and altered histological architectures of liver and kidney tissues (El-Naggar et al. 2019a). In the present study, administration of C.M alone for 15 days (sub-acute), or 90 days (sub-chronic) did not significantly alter the body weight changes when compared to their control. Administration of C.M./EDTA $(10 \mathrm{mg} / \mathrm{Kg})$ for 15 days did not alter the hematological parameters, however, administration of C.M./EDTA $(10 \mathrm{mg} / \mathrm{Kg})$ for 90 days alter the differential leucocytes. This finding could be due to the toxic effect of EDTA byproducts on the bone marrow or spleen. Previous study showed that EDTA could alter hematological parameters post chronic administration (El-Naggar et al. 2019b; El-Naggar and El-Said 2020). The ALT, AST, urea, and creatinine biomarkers did not alter post administration with C.M. alone or with C.M./EDTA for 15 days, however, these parameters increased post 90 days of C.M./EDTA (10 mg/Kg) administration. These findings postulated that the administration of C.M./EDTA altered the biochemical and physiological features of liver and kidney tissues that might be due to the formation of some toxic compounds upon the boiling of EDTA with beans. These findings were agreed with El-Naggar et al. (2019a) who reported that administration of C.M./EDTA increased liver and kidney biomarkers.

Furthermore, previous studies reported the toxic effects of EDTA administration in experimental animals that promoted biochemical alterations (Wang et al. 2004; Khalil et al. 2008). 
Previous study demonstrated that multiple sessions of intravenous EDTA chelation therapy with or without vitamin C decrease the oxidative stress and lipid peroxidation (Roussel et al. 2009). In the present study, the levels of oxidants/antioxidants biomarkers did not change post 15 days of administration of C.M. alone or with C.M./EDTA. These results postulated that subacute administration of C.M./EDTA was not toxic at the subacute phase, however, post 90 days (sub-chronic) was toxic due to the alteration in oxidants/antioxidants homeostasis. This disturbance in antioxidant status upon administration of C.M./EDTA to mice might be due to the negative influence of EDTA on enzyme activities. GonzálezCuevas et al. (2011) reported that EDTA treatment induces the activity of antioxidant enzymes, decreases lipid peroxidation, hepatic inflammation, and liver fibrosis in experimental animals. Furthermore, it has been reported that EDTA showed neuroprotective potential against lead toxicity due to their ability to react faster with peroxyl radicals there by reducing the severity of biochemical variable indicative of oxidative damage (Basha et al. 2013).

In experimental animals, EDTA administration promoted histological alterations (Wang et al. 2004; Khalil et al. 2008; Ramadan et al. 2016). Consistent with the hematological and biochemical findings, the present study indicated that the effect of C.M./EDTA administration for 15 days did not alter both liver and kidney architecture, however, post 90 days of administration, C.M./EDTA $(10 \mathrm{mg} / \mathrm{Kg})$ induced histopathological alterations in the liver and kidney tissues. Similar findings were found on the histopathological alterations of liver and kidneys upon administrating the experimental animals with C.M./EDTA for long time (El-Naggar et al. 2019a). Wang et al. (2004) reported that there was marked hepatocyte damage in rats administered with EDTA. Abdel-Wahhab et al. (2002) reported that EDTA

administration showed kidney dysfunction. Furthermore, Ramadan et al. (2016) reported that having food contaminated with EDTA caused degeneration in the interstitial cells in mice and decreased the fertility.

\section{Conclusion}

The present study reported that sub-acute administration of C.M./EDTA at $10 \mathrm{mg} / \mathrm{Kg}$ did not show significant alterations on the hematological, biochemical, and histopathological investigations. However, sub-chronic administration did alter the functionality of liver and kidney organs.

\section{Declarations}

\section{Acknowledgments}

This study is based upon work supported by STDF-Grant no. 34792 from the Science and Technology Development Fund, the Ministry of Scientific Research, Egypt.

\section{Availability of data and materials}

The datasets used and/or analyzed during the current study are available from the corresponding author on reasonable request and included in this article. 


\section{Author contribution}

Sabry Ali El-Naggar: conceptualization, funding acquisition, writing original draft, and supervision. Mona Elwan and Doaa Ibrahim Kabil: conceptualization, data analyses, visualization, writing original draft preparation. Abdelaziz Zidan: investigation, writing review and editing. Karim Samy El-Said:

conceptualization, funding acquisition, writing original draft, supervision, investigation, writing review and editing.

\section{Ethics approval}

The institutional animal care committee at the Zoology Department, Faculty of Science, Tanta UniversityEgypt, approved the experimental design (IACUC-SCI-TU-0098).

\section{Consent for publication}

Not applicable.

\section{Competing interests}

All authors declared that there is no competing interest.

\section{Funding}

This study is based upon work supported by STDF-Grant no. 34792 from the Science and Technology Development Fund, the Ministry of Scientific Research, Egypt.

\section{References}

Abdel-Aleem WM, Abdel-Hameed S, Latif S (2019) Effect of soaking and cooking on nutritional and quality properties of faba bean. Food and Dairy Sci 10:389-395

Abdel-Wahhab MA, Amer HA, Hassan NS, Hassan AM, Naguib KM (2002) Effects of garlic and cabbage extracts on fuminisin-induced toxicity in rats. Egypt Society Toxicol 26:1-12

Aebi H (1984) Catalase in vitro. Methods of Enzymol 105:121-126

Allain CC, Poon LS, Chan CS, Richmond W, Fu PC (1974) Enzymatic determination of total serum cholesterol. Clin Chem 20:470-475

Baginsky C, Peña-Neira A, Cáceres-Mella A, Hernández T, Estrella I, Morales H, Pertuzé R (2013) Phenolic compound composition in immature seeds of fava bean (Vicia faba L.) varieties cultivated in Chile. Food Composition Analysis 31:1-6

Bancroft J, Gamble M (2002) Theory and practice of histological techniques 5th Edition, eds. Bancroft, JD and Gamble, M., Churchill Livingstone 
Basha MP, Begum S, Mir BA (2013) Neuroprotective actions of clinoptilolite and ethylenediaminetetraacetic acid against lead-induced toxicity in mice Mus musculus. Toxicol Int 20:201207

Bingham SA, Welch AA, McTaggart A, Mulligan AA, Runswick SA, Luben R et al (2001) Nutritional methods in the european prospective investigation of cancer in norfolk. Public Health Nut 4:847-858

Burstein M, Scholnick HR, Morfin R (1970) Rapid method for the isolation of lipoproteins from human serum by precipitation with polyanions. Lipid Res 11:58-95

Chan E, Lim Y, Wong S, Lim K, Tan S, Lianto F (2009) Effects of different drying methods on the antioxidant properties of leaves and tea of ginger species. Food Chem 113:166-172

El-Naggar S, El-Said K (2020) Antitumor efficacy of EDTA co-treatment with cisplatin in tumor-bearing mice. Brazilian J Pharm Sci 56:e18536

El-Naggar S, El-Said K, Elwan M, Mobasher M, Mansour F, Elbakry M (2019a) Toxicity of bean cooking media containing EDTA in mice. Toxicol and Indus Health. 63:1-10

El-Naggar S, El-Said K, Othman S, Mansour F, Kabil D, Khairy M (2019c) Cooking with EDTA reduces nutritional value of Vicia faba beans. Biotechnol Reports. 22:e00322

El-Naggar SA, El-Said KS, Mobasher M, Elbakry M (2019b) Enhancing antitumor efficacy of cisplatin low dose by EDTA in Ehrlich ascetic carcinoma bearing mice. Brazilian Archives of Biol and Technol 62:e19180716

El-Nasharty A (2021) Phytochemical screening and vitamins quantitation of broad beans (Vicia faba) cooked with EDTA. Faculty of Specific Education, Tanta University, Egypt (Thesis)

Farajvand M, Kiarostami V, Davallo M, Ghaedi A (2017) Optimization of solvent terminated dispersive liquid-liquid micro-extraction of copper ions in water and food samples using artificial neural networks coupled bee algorithm. Bull Environmental Contamination Toxicol 100:402-408

Feril JR, Ogawa K, Watanabe A, Ogawa R, Cui Z, Kondo T (2017) Anticancer potential of EDTA: a preliminary in vitro study. Mathews $\mathrm{J}$ Cancer Sci 2:009

Ferrero ME (2016) Rationale for the successful management of EDTA chelation therapy in human burden by toxic metals. BioMed Res Int 2016:1-13

Fossati P, Prencipe L (1982) Serum triglycerides determined colorimetric ally with an enzyme that produces hydrogen peroxide. Clin Chem 28:2077-2080

González-Cuevas J, Navarro-Partida J, Marquez-Aguirr AL, Bueno-Topete MR, Beas-Zarate C, ArmendárizBorunda J (2011) Ethylenediaminetetraacetic acid induces antioxidant and anti-inflammatory activities in 
experimental liver fibrosis. Redox Rep 16:62-70

Gunathilake K, Ranaweera K, Rupasinghe H (2018) Effect of different cooking methods on polyphenols, carotenoids, and antioxidant activities of selected edible leaves. Antioxidants 7:117-128

Hefni M, Witthoft C (2014) Folate content in processed legume foods commonly consumed in Egypt. LWT -Food Sci. Technol. 57:337-343

Khalil AH, Mansour EH (1995) The effect of cooking, autoclaving and germination on the nutritional quality of faba beans. Food Chem 54:177-182

Khalil WK, Ahmed KA, Park MH, Kim YT, Park HH, Abdel-Wahhab MA (2008) The inhibitory effects of garlic and Panax ginseng extract standardized with ginsenoside Rg3 on the genotoxicity, biochemical and histological changes induced by ethylenediaminetetraacetic acid in male rats. Archives of Toxicol 82:183-195

Kobayashi W, Yokokura S, Hariya T, Nakazawa T (2015) Two percent ethylenediaminetetraacetic acid chelation treatment for band-shaped keratopathy, without blunt scratching after removal of the corneal epithelium. Clin Ophthalmol 9:217-233

Lamas GA, Boineau R, Goertz C, Mark DB, Rosenberg Y, Stylianou M (2014) EDTA chelation therapy alone and in combination with oral high-dose multivitamins and minerals for coronary disease: The factorial group results of the Trial to Assess Chelation Therapy. American Heart J 168:37-44

Lanigan RS, Yamarik TA (2002) Final report on the safety assessment of EDTA, calcium disodium EDTA, diammonium EDTA, dipotassium EDTA, disodium EDTA, TEA-EDTA, tetrasodium EDTA, tripotassium EDTA, trisodium EDTA, HEDTA, and trisodium HEDTA. Int J Toxicol 21:95-142

Mubaiwa J, Fogliano V, Chidewe C, Linnemann AR (2017) Hard-tocook phenomenon in bambara groundnut (Vigna subterranean (L.) Verdc.) processing: options to improve its role in providing food security. Food Reviews Int 33:167-194

Paglia DE, Valentine WN (1967) Studies on the quantitative and qualitative characterization of erythrocyte glutathione peroxidase. Lab Clin Med 70:158-169

Paoletti F, Mocali A (1990) Determination of superoxide dismutase activity by purely chemical system based on NAD(P)H oxidation. Methods Enzymol 186:209-220

Podsedek A, Sosnowska D, Redzynia M, Koziolkiewicz M (2008) Effect of domestic cooking on the red cabbage hydrophilic antioxidants. Int J Food Sci Technol 43:1770-1777

Ramadan M, Sakr D, Abou-Egla M, Noegy NH (2016) Evaluation of the effect of EDTA contaminated food on the fertility of male mice. Animal Poultry Prod 7:233-239 
Rawson A, Hossain M, Patras A, Tuohy M, Brunton N (2013) Effect of boiling and roasting on the polyacetylene and polyphenol content of fennel (Foeniculum vulgare) bulb. Food Res Int 50:513-518

Roussel AM, Hininger-Favier I, Waters RS, Osman M, Fernholz K, Anderson RA (2009) EDTA chelation therapy without added vitamin $\mathrm{C}$, decreases oxidative DNA damage and lipid peroxidation. Alter Med Review 14:56-61

Wang H, Wei W, Shen YX, Dong C, Zhang LL, Wang NP (2004) Protective effect of melatonin against liver injury in mice induced by Bacillus Calmette-Guerin plus lipopolysaccharide. World $\mathrm{J}$ gastroenterol 10:2690-2696

\section{Figures}

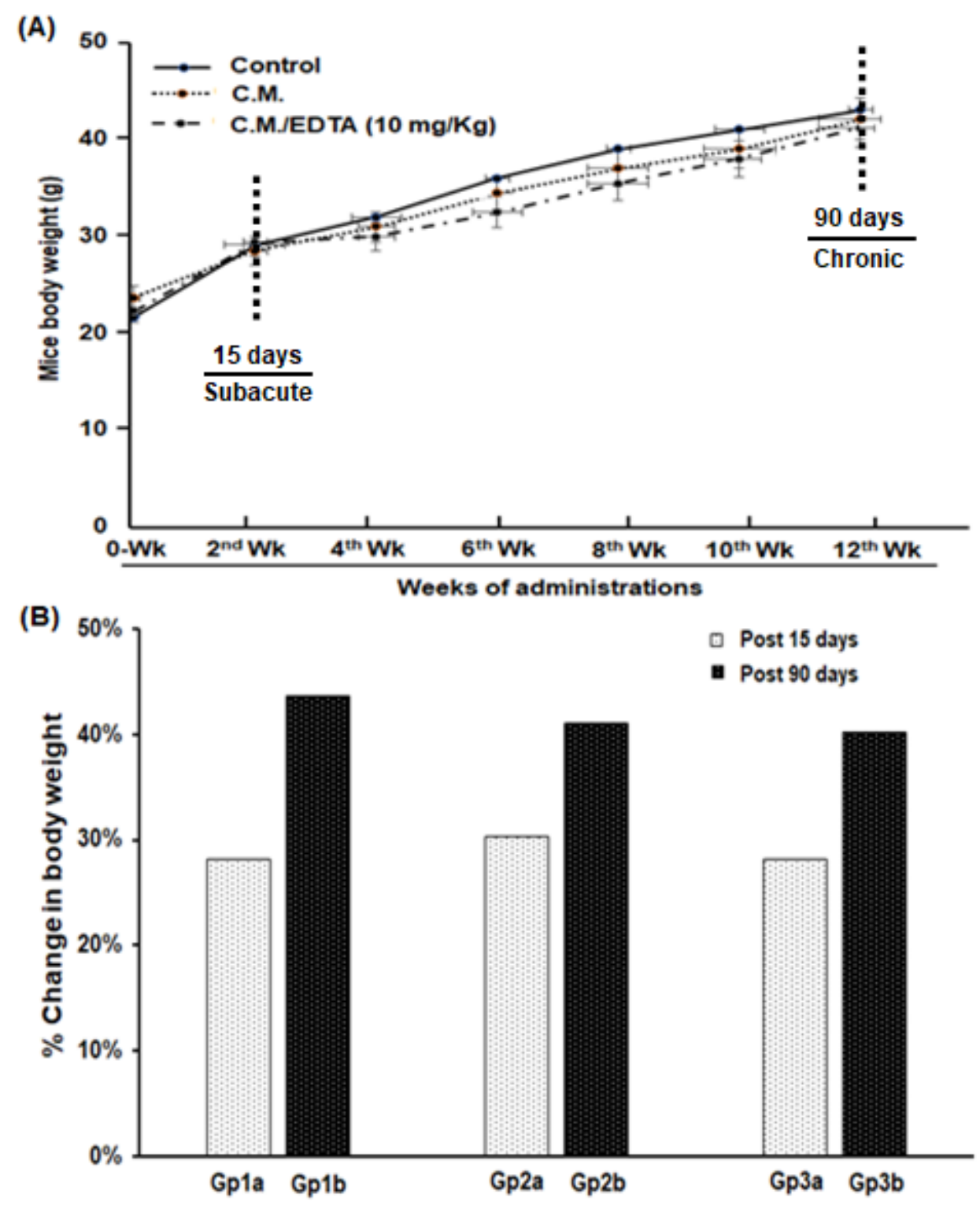

Figure 1 
(A) Kinetics of body weight changes (B) Percentages of body weight changes in all groups under the study. Gp1a and Gp1b: control administered with H2O, Gp2a and Gp2b: mice administered with cooking media (C.M.) alone, Gp3a and Gp3b: mice administered with C.M./EDTA (10 mg/Kg) Gp1a, Gp2a, and Gp3a were administrated for 15 days, Gp1b, Gp2b, and Gp3b were administrated for 90 days.

(A)

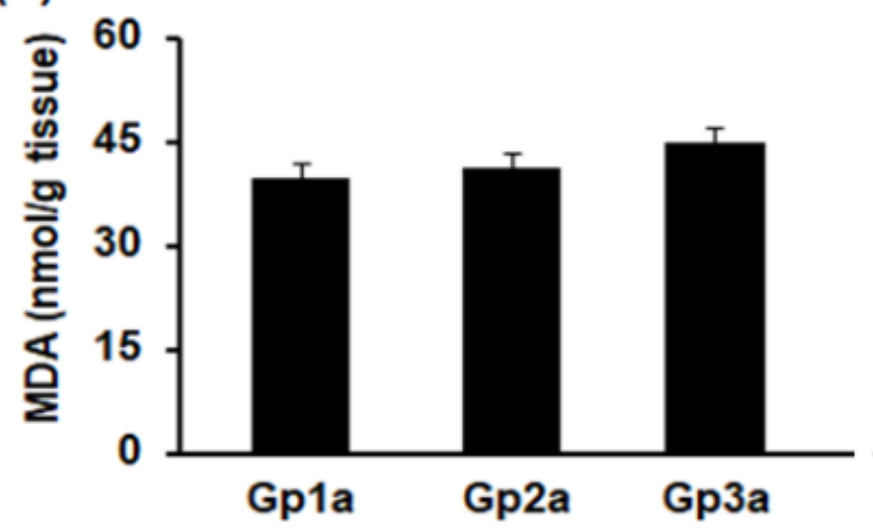

(B)

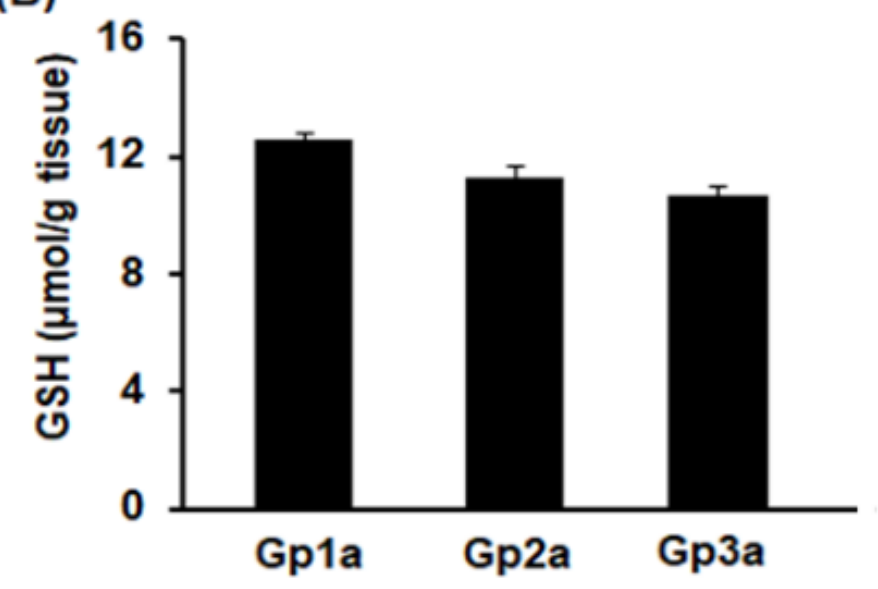

(C)

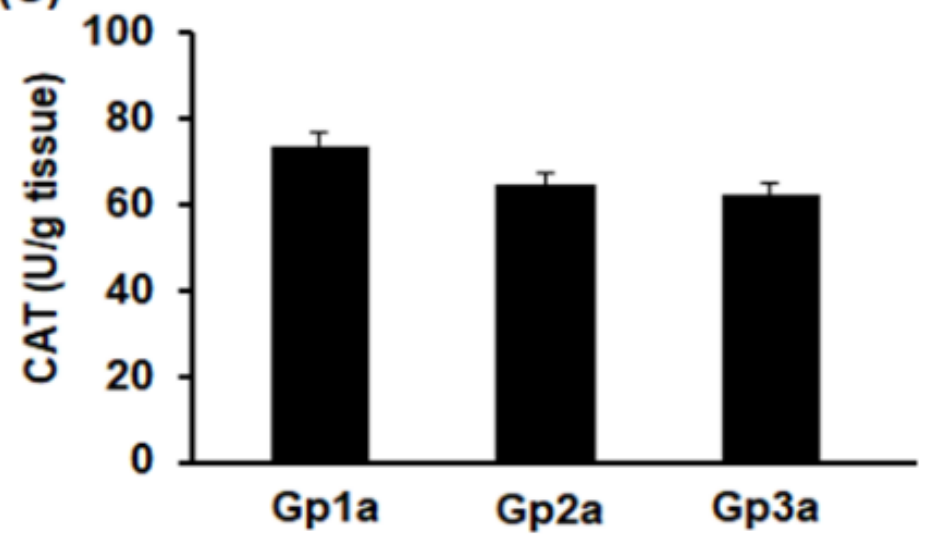

(D)

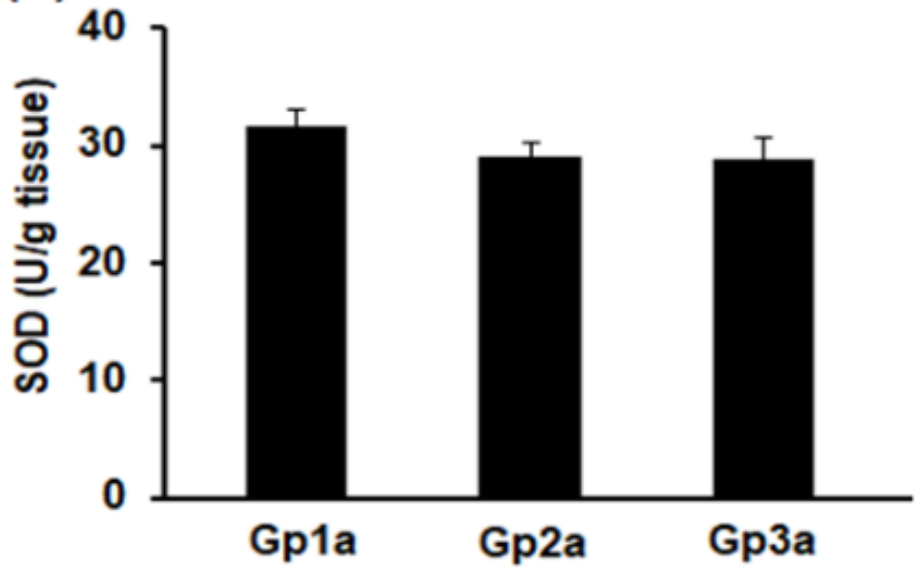

Figure 2

Oxidative stress biomarkers post 15 days. (A) Malondialdehyde (MDA), (B) Reduced glutathione (GSH), (C) Catalase (CAT), and (D) Superoxide dismutase (SOD) in all groups under the study. Gp1a: control administered with $\mathrm{H} 2 \mathrm{O}$, Gp2a: mice administered with cooking media (C.M.) alone, Gp3a: mice administered with C.M./EDTA (10 mg/Kg) Gp1a, Gp2a, and Gp3a were administrated for 15 days. 

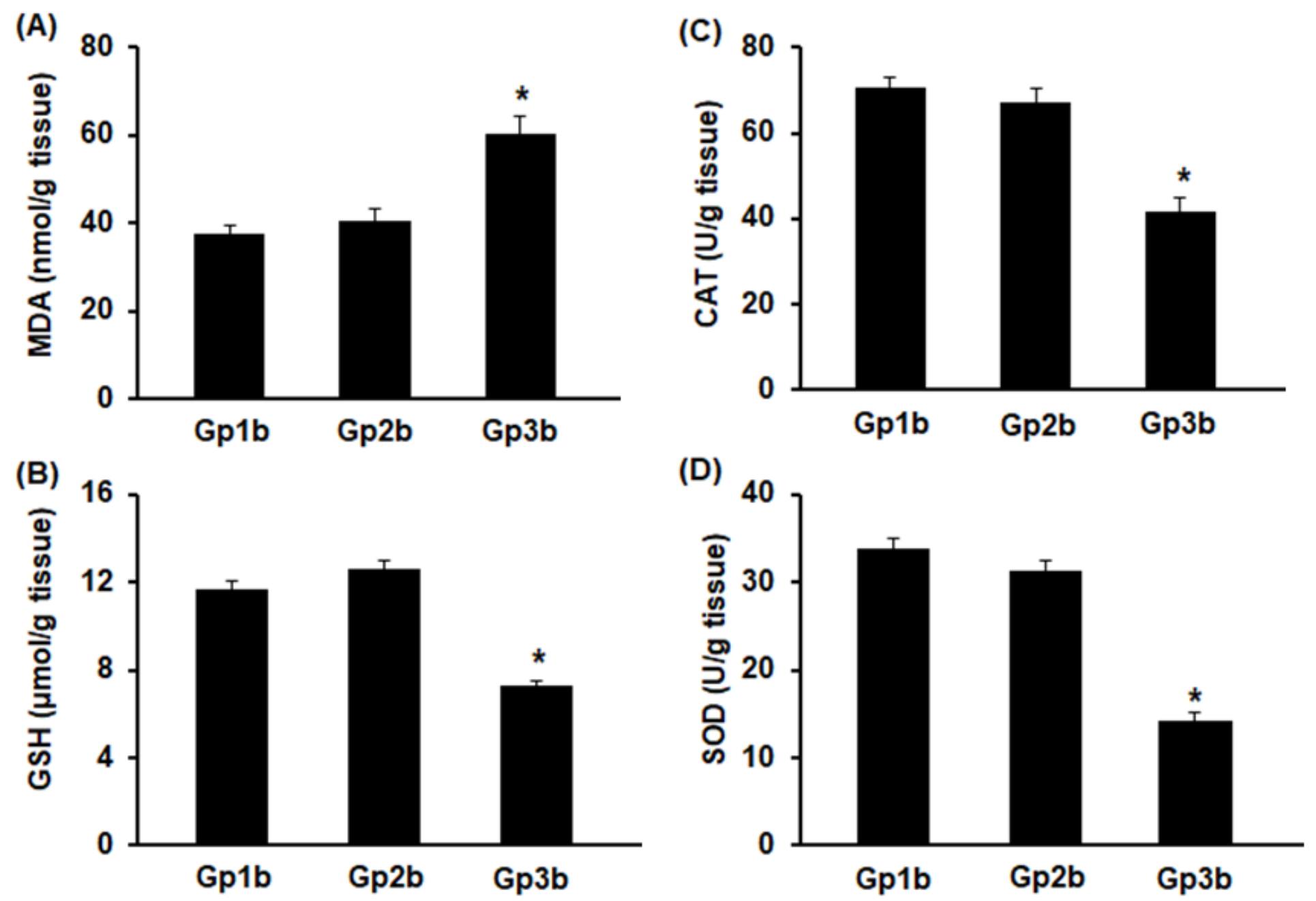

Figure 3

Oxidative stress biomarkers post 90 days. (A) Malondialdehyde (MDA), (B) Reduced glutathione (GSH), (C) Catalase (CAT), and (D) Superoxide dismutase (SOD) in all groups under the study. Gp1b: control administered with $\mathrm{H} 2 \mathrm{O}$, Gp2b: mice administered with cooking media (C.M.) alone, Gp3b: mice administered with C.M./EDTA (10 mg/Kg). Gp1b, Gp2b, and Gp3b were administrated for 90 days.

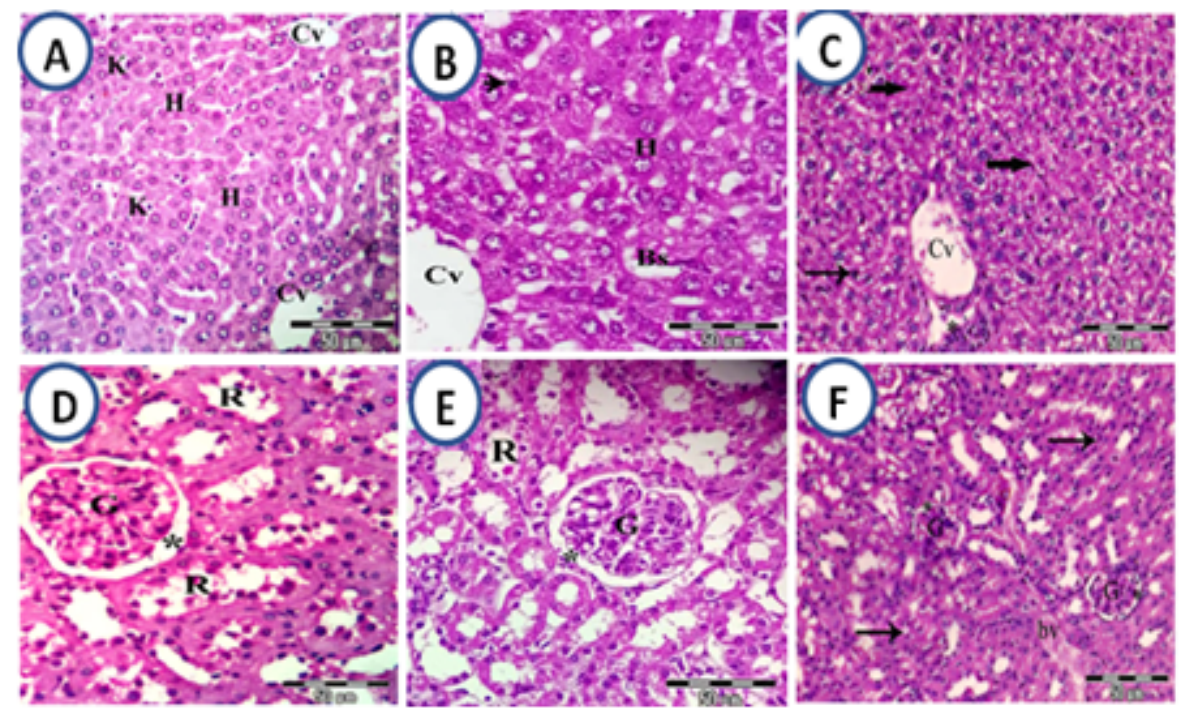




\section{Figure 4}

Liver and kidney sections stained with $\mathrm{H}$ \& $\mathrm{E}$ of different groups under the study post 15 days of administration. (A, B, and C) Liver sections of control, C.M., and C.M./EDTA administered mice (10 $\mathrm{mg} / \mathrm{Kg})$. (D, E, and F) kidney sections of control, C.M., and C.M./EDTA administered mice $(10 \mathrm{mg} / \mathrm{Kg})$.
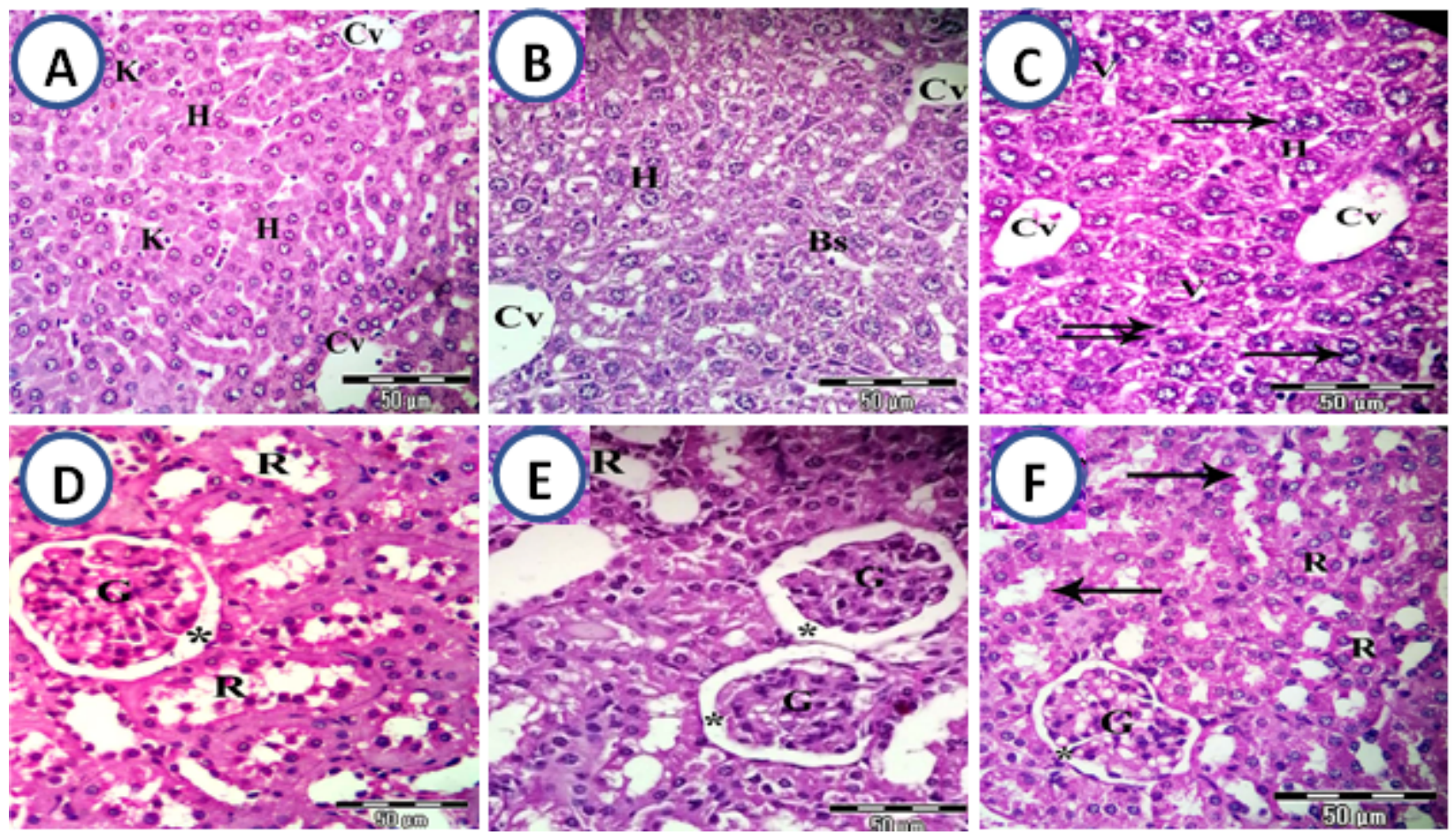

\section{Figure 5}

Liver and kidney sections stained with $\mathrm{H} \& \mathrm{E}$ of different groups under the study post 90 days of administration. (A, B, and C) Liver sections of control, C.M., and C.M./EDTA administered mice (10 $\mathrm{mg} / \mathrm{Kg})$. (D, E, and F) kidney sections of control, C.M., and C.M./EDTA administered mice $(10 \mathrm{mg} / \mathrm{Kg})$. 